Stephen M. Mutula:

\title{
A Framework for Integrating Information Ethics (IE) in the Curricula for Africa
}

\begin{abstract}
:
The debate about embedding information ethics (IE) in the curriculum in Africa is gaining momentum as scholars from developed and developing world engage on the subject. Some research publications are starting to emerge on information ethics in Africa but so far they have been confined to addressing the extent to which information ethics is necessary, who should offer information ethics and why, who should be taught and at what levels, the duration of offering the course/program and the content that should be included in the curriculum. Little attention has been placed on the theoretical framework that should underpin IE curriculum for Africa as well as the sources of IE content for the curriculum. This paper therefore addresses the following issues: rationale for integrating information ethics in the curricula in Africa; theoretical and institutional framework for IE curriculum; potential sources of content for information ethics curricula, challenges of integrating information ethics into the curricula in Africa and prospects for integrating IE into the curricula in Africa.
\end{abstract}

\section{Agenda:}

Introduction 30

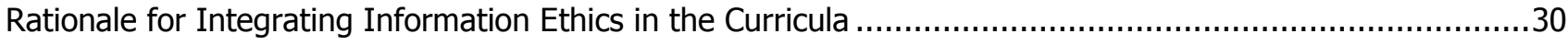

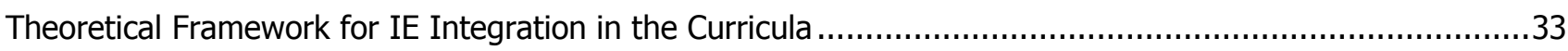

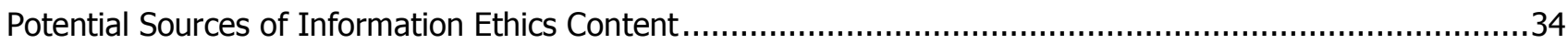

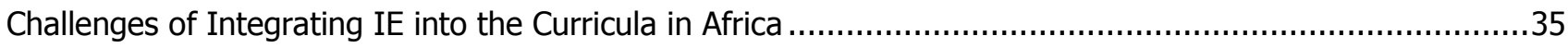

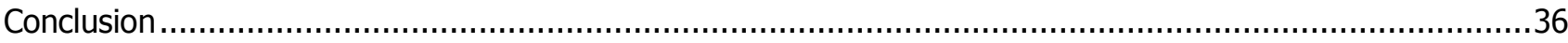

Author:

Stephen M. Mutula:

- Department of Library \& Information Studies, University of Botswana, Private Bag 0022, Gaborone, Botswana

- Tel: +267-3552627(w), +267-71424991

- Email: mutulasm@mopipi.ub.bw 


\section{Introduction}

The debate about embedding information ethics in the curriculum in Africa is gaining momentum as scholars from developed and developing world engage on the subject. Ocholla (2009) in an empirical study on the state of information ethics integration in the curricula of LIS schools in Africa investigated several perspectives such as the extent to which information ethics was necessary, who should offer information ethics and why, who should be taught and at what levels, how long should be the duration of the course/program and what should be included in the curriculum?. This paper builds on Ocholla's work and proposes a framework for information ethics curricula for tertiary education in Africa. Besides, the paper explores the sources that would provide theory, corpora of knowledge and philosophical underpinning for the development of information ethics for Africa.

Understanding the subject of information ethics is important in order to appreciate the dynamics and implications of its integration in the curricula for Africa. Britz \& Buchanan (2009) outlined the scope of information ethics as focusing on the moral questions relating to the life cycle of information as it pertains to its generation, gathering, organization, storage, retrieval and use. They point out that as a field, information ethics broadly examines issues related to privacy, security, access to information, intellectual freedom, quality and integrity of information as well as intellectual property rights. Additionally, they state that the broader domain of professional ethics is of great import, encompassing the ways professionals engage with, respond and react to those ethical issues. Furthermore, they identified stakeholders of information ethics as creators and/or distributors of information products and services, information mediators including librarians and information users. Finally, they see ICT as an important tool for completing the broader domain of information ethics as it supports the different information life cycle activities and plays the important role of shaping the understanding of the information ethics field.

As debate and dialogue on information ethics integration in the curriculum for Africa gathers pace, the continent and its people faces various challenges that stand in the way of attaining an information society for all. These challenges include but are not limited to inadequate or complete lack of an enabling policy \& legal environment for digital inclusion, information illiteracy, paucity of local content, bad governance and lack of democratic institutions. Ocholla (2009) adds to these challenges rapid technological development and its use at home and cybercafés; limited knowledge of information ethics among information workers; lack of qualified staff to teach the subject of information ethics; government censorship of information; poor ICT infrastructure; digital divide, etcetera. Besides, Britz et al. (2008) and Britz \& Buchanan (2009) content that information ethics integration in education is affected by non-neutrality of ICTs; lack of clear responsibility for information generation and dissemination; issues of privacy and accuracy; the dominance of western model of intellectual property; bio-piracy; cultural diversity; globalization; gender inequality; information imperialism including, control and distribution of patents, technical knowledge and scholarly publications.

This paper therefore addresses four areas on information ethics that have implications for Africa's tertiary education and scholarship. These areas include:

1. Rationale for integrating information ethics in the curricula in Africa

2. Theoretical and institutional framework for IE integration in the curricula

3. Potential sources of content for information ethics curricula

4. Challenges of integrating information ethics into the curricula in Africa.

\section{Rationale for Integrating Information Ethics in the Curricula}

Since 2007, there has been concerted efforts through the partnership of information science scholars from southern African library schools (University of Botswana, University of Pretoria \& University of Zululand), supported by their counterpart at the University of Wisconsin Milwaukee (USA), to develop information ethics curriculum for Africa. The first initiative to discuss integration of information ethics into Africa's curricula brought together academics, government representatives and scholars from the international community at a conference that was held at the University of Pretoria (Tshwane) in South Africa in February 2007. The outcome from this conference was the 'Tshwane declaration on information ethics in Africa' which called for the mobilization of academic research on 
information ethics within the scholarly community. This was followed by two years later workshop on egovernment and information ethics in February 2009 that was Held at Mount Resort Magaliesburg, South Africa. These two events culminated in the information ethics conference for Africa that would be held at the University of Botswana in September 2010 to illuminate the unique problems and solutions of integrating information ethics in the curricula of African tertiary education. Britz, Mutula \& Ocholla (2009) in their strategic plan for information ethics integration in Africa's tertiary education envisaged creating a long term partnership between the University of Wisconsin-Milwaukee (USA), the University of Botswana \& the University of Zululand (South Africa). The partnership would facilitate curriculum development and faculty training for library and information science schools in Africa. The partnership would also focus on information ethics as an interdisciplinary field dedicated to critical reflection on moral values and practices related to production, storage, and distribution of information, as well as the related information systems, infrastructures, and policies that are embedded in modern culture and society.

The importance of integrating information ethics into the curricula for Africa cannot be over emphasised. Information ethics would enable information professionals to engage in ethical reasoning by determining what is wrong or right in a dilemma situation. Capurro (2010) states that information ethics opens up space of critical reflection for all stakeholders on established moral norms and values. It also serves as a catalyst for a social process and is a space for retrieving the rich African cultural memory necessary to our field. This cultural memory permits reshaping African identities and contribute to the world's information and communication cultures. Mutula \& Raseroka (2006) noted that in most parts of sub-Saharan Africa and more so in Southern Africa, children up to the ages of 15 are left out when information services and programs are designed or provided. The children in Africa often graduate into adulthood without acquiring the necessary information seeking skills. This is exacerbated by the fact that there is a general lack of reading culture in Africa (excluding reading for passing examinations) and the threat that this poses could be costly particularly with regard to the inability for the African society to fully harness the emerging information society whose component is independent access and use of information for socioeconomic development. The lack of a culture of reading has a negative impact on the exploitation of available accurate information that influences per- sonal attitudes and behaviors towards life issues such as the HIV/AIDS pandemic. Yet, young people in the whole of Africa have the potential to become the engine that helps create the information society and catalyse the attainment of Millennium Development Goals (MDGs).

Ocholla (2009) is of the view that information ethics integration in the curriculum would support information professionals in their understanding and development of ethical values and morals with regard to protection (privacy \& confidentiality). This would also create professional identity built upon information value systems, allow professionals to understand today's information and knowledge driven society, enable them understand the intricacies of access to information, etcetera. It is also expected that once information ethics is integrated into the curricula, information professionals in Africa would be better prepared to participate in debates surrounding information ethics thus, allowing their fuller engagement in Africa's economic, social and political development. Britz \& Buchanan (2009) are of the view that as information professionals, we have a responsibility to provide unfettered access to information thus, promoting intellectual freedom and rights to information. Besides, information retrieval systems, digital libraries, web 2.0, and other have democratized creation, storage and dissemination of information using technology that lack neutrality but biased by culture, ideology, and temporality. They conclude that understanding cultural ethics is important because intercultural ethics allows us to consider the global nature of information work. Furthermore, equipping information workers with information ethics would enable information mediators in verifying quality, and accuracy of information to clients.

Information ethics integration in the curriculum has become more important than before because of transformative government that are being implemented the world over, using ICTs. Through egovernment implementation, many jurisdictions expect to advance democracy, good governance, transparency and accountability (United Nations, 2008). Most governments are now enacting ICT policies that put the people at the centre of state operations to enhance socio-economic and political development. With increasing implementation of egovernment across the world, moral issues relating to this phenomenon must be addressed because egovernment implementation raises several ethical issues such as usability of system/service; system security; systems interoperability; intellectual property rights; freedom of information; universal ac- 
cess; privacy and more. Carbo (2007) observes that these issues arise because governments collect and store a lot of information on citizens and private enterprises such as corporate filing, tax and regulatory information. However, little attention is being paid to these ethical aspects and others such as whether people trust e-government or how the cultural differences affect individuals' trust in government and their perceptions of how government affect their human dignity.

Ethical violations in governance have been of concern for proponents of good governance and advocates of respect for human rights. In developing countries, cases of poor governance, limited press freedom \& free speech, regulated economic environments, poor accountability and service delivery are often reported. Neumayer (2006) notes that good governance encompasses political legitimacy, administrative accountability, financial accountability, transparency, openness, and the rule of law. Transparency as a major component of governance means that decisions taken and their enforcement are executed based on clearly stipulated rules and regulations that are known to all stakeholders. Democracy another important aspect of good governance entails free and fair elections, protection of minorities, the rule of law, separation of powers, and protection of civil liberties (Raaflaub et al., 2007). In a democracy the supreme power is vested in the people and exercised by them directly or indirectly through a system of representation. Taken further, modern democracy is founded on the principle of Universal Human Rights where the will of the people is the basis of the authority of government (Hamelink, 2003). The tenets of good governance such as accountability, transparency and respect for human rights therefore need to be promoted in the curriculum as ethical values in order to ensure that human dignity and fundamental human rights are appreciated and practiced by the populace. The government as the major actor in the governance process must create an enabling environment for citizen participation in the decision making process and service delivery systems. When principles of democratic governance are not exercised legitimately or transparently by the authorities as often happen in most African countries, ethical values are violated. Ethical values in e-government would also include promoting principles that espouse creative multilingual content and universal access to information and communication technologies in order to address the problem of information poverty in Africa (Mutula, 2008).
E-government environment needs a legal oriented framework necessary to cater for cyber laws, consumer protection, and the security of transactions (Department of IT eTechnology Group -India, 2003). A consumer protection framework would deal with uncompetitive behaviour in the market and create a level playing field for all businesses. OECD countries have developed guidelines for consumer protection in the context of e-commerce that provide a solid base for consumers to receive the same level of protection when they shop online as they would if they bought from a local store. Besides, OECD, the European Union member states have on their part taken measures to ban the sale of inaccessible technology products while enhancing the growth of assistive technology. National strategies of member states emphasise interoperability of products, universal service policies for electronic communications, affordable pricing of network, and interactive content. In 1999, the European Commission launched the eEurope initiative which among other things recognized accessibility for disabled users such as the blind, deaf people or people with learning impairments. Governments in the EU member states are encouraged to cater for disabled people when they launch national initiatives in the framework of eEurope (European Commission, 2005).

Koren (1997) in a published study, Tell Me! The Right of the Child to Information concludes that the right to information is a fundamental human right, which is crucial to human development and...important for...every human being. UNESCO (2008) is explicit about commitment to the free flow of information and access to knowledge sources ... for "the wide diffusion of culture, and the education of humanity for justice and liberty and peace... Mason (1986) is of the view that information forms the intellectual capital from which human beings craft their lives and secure dignity. Consequently, people's intellectual capital is impaired whenever they lose their personal information without being compensated for it, when they are precluded access to information which is of value to them, when they have revealed information they hold intimate, or when they find out that the information upon which their living depends is in error.

Britz et al. (2009) note that information ethics provides the appropriate lens for dealing with a wide range of ethical problems and challenges facing Africa. The integration of information ethics in the curricula of African education could help address the onslaught of western cultural cinematography and international intellectual property models. The 
current information society dispensation that is information driven requires ability to sieve through plethora of information resources to identify what is accurate, appropriate and relevant. Besides, digital divide in Africa is pervasive and creates many other inequalities that infringe on the rights of individuals. Through access to information, citizens can be equipped to participate in democratic governance through effective participation in elections, engaging their governments and participating in economic development. Lack of access to information creates poverty and social inequality.

\section{Theoretical Framework for IE Integration in the Curricula}

The concept of information ethics is yet to be understood and appreciated in African scholarship as reflected by the lack of research and publications on the subject. This fact is reiterated by Capurro (2010) who notes that information ethics in Africa is a young academic field and not much has been published on the role that African philosophy can play in thinking about the challenges arising from the impact of ICT on Africa societies and cultures. Yet, in developed world especially, in North America and Asia, information ethics integration in the curricula has been embraced (Buchanan, 2004; Ocholla, 2008; Vagaan, 2003). Froehlich (2005) describes information ethics as an' interdisciplinary field of study dedicated to the critical reflection on the ethical values and practices related to the production, storage and distribution of information as well as the related information systems, infrastructures, and policies embedded in modern culture and society. Capurro and such other scholars as Luciano Floridi, Stephen Almagno and Robert Hauptman (Ocholla, 2008) are credited for playing a leading role in anchoring information ethics discourse in library and information science discipline. Capurro (1998) however, acknowledges that information ethics has grown and extended into other disciplines such as computer science, management information systems, mass media, journalism and law. To him, information ethics embraces relationship between information and human rights and responsibility, including ethical issues of information production, information collection and classification, information access, information dissemination, information law and policy.

Despite its pioneering place in LIS, information ethics epistemology resides in applied ethics which provides the basic theoretical framework on which the pedagogical foundation and practice of the subject can be constructed and applied. Information ethics pervade systems where information or any other form of content is generated, stored, communicated, applied and owned. In this context, Ocholla (2009) citing (Fallis, 2007) identifies some of the theories underpinning information ethics as: consequence-based and rights based theories. Consequence-based theories are founded on utilitarianism and posit that 'what distinguishes right actions from wrong actions is that they actions have better consequences. In contrast, rights-based theories operate on the premise that the right thing to do is determined by the rights that human being has'. Besides, duty-based theories also called deontological theories are relevant in understanding the subject of ethics. The word Deon is Greek which basically means duty or obligation. The main proponent of this ethical theory was the German philosopher Immanuel Kant (1724-1804). Kant believed that there are higher principles that are good in every time, every culture, and every situation. When faced with an ethical dilemma, he believes we should ask ourselves: "To whom do I owe a duty and what duty do I owe them?" To answer these questions, Kant proposed that we use reason to identify the higher principles we should live and act by. He named two principles, or categorical imperatives, that would guide all our actions in this ethical framework: Universal applicability \& respectful of others. He observed that we should not act one way in some situations or with some people and another way in others. Our actions should be consistent across the board. With regard to respectful of others Kant's view is that, the fact that human beings can reason gives us greater value than anything else. Never treat people as a means to an end, even if you believe the ends are positive.

The other underpinning theory in information ethics is Utilitarianism which promotes the idea that actions are judged right or wrong according to the amount of happiness that comes from those decisions (Moore, 1988). Consequently, an individual makes decisions according to which one would provide the greatest good for the greatest number of people. Utilitarian theory believes the end justifies the means. The ethics theory (Fallis, 2007) distinguishes right actions from wrong actions. It posits that there are ethical duties that human beings must obey regardless of the consequence. Besides, the right thing to do is determined by the rights that human beings have, as enunciated by UN Declaration of Human Rights (Carbo, 2007) such as love, affection, kindness, gentleness, warm-heartedness, and human dignity. Egoism is another theory that 
could be used to explain information. It posits that right and wrong is based on the consequences to self. Choice is for purpose of putting self interest ahead of anything else. Weakness of this theory is that it can lead to unethical behaviour as long as it satisfies one's ego. It may promote infringing on the rights of others for selfish ends. Collectively, these theories discussed here and others should be interrogated by scholars to determine perspectives of information ethics integration in Africa's tertiary education.

Ocholla (2009) observes that the problem with most of theories of ethics is the difficulties faced in their applications particularly because of what he perceives as the contradictions one encounters when attempting comparisons. He argues for example, that the interpretation and implementation of rights across communities around the world is not uniform. For instance, marginalized groups such as children, women, people with disabilities, and others discriminated against on account of race, creed, religion, social status, age, etc may not necessarily benefit from human rights that others enjoy. These challenges may be even more pronounced when applied to the African environment with many cultures, tribes and ethnic groups. In this case African philosophy of ubuntu may need to be explored in the context of how it can inform the information ethics curricula for Africa. Ubuntu is a concept widely used among bantu speaking groups in east and southern Africa which translated means 'we are people because of other people' and ' I am who I am because of who we all are' (Ocholla, 2008). Ramose (2002) adds that ubuntu is a central concept of social and political organization in African philosophy and emphasizes sharing and caring for one another. Brannigan (2005) refers to it as 'to be is to belong'.

\section{Potential Sources of Information Ethics Content}

As dialogue about integrating information ethics in the curricula in Africa among scholars intensifies, the issue of content need addressing. The issue of content for information ethics curricula has not been systematically addressed. Ocholla (2009) in a study of information ethics education and training identified lack of well defined content as a major challenge. The African philosophy along with the ethics theories discussed above may provide a good starting point for developing content for the information ethics curricula. Capurro (2010) observes that there is a long history of information ethics in Africa especially, with regard to oral and written traditions. In this regard, further interrogation of the ubuntu philosophy may provide a framework for developing information ethics curricula that is relevant for Africa. From the international perspective, the World Summit on Information Society (WSIS) Principles of Declarations expect nations to take specific actions toward improving access through, encouraging linguistic diversity, multiculturalism, promoting development of local content; preservation of cultural collections and documentary records; harnessing indigenous knowledge; connecting public libraries, cultural centres, museums, and adapting all primary and secondary school curricula to the needs of information society (WSIS, 2003, 2005). These perspectives on WSIS provide a framework for developing information ethics content.

Besides WSIS, Millennium Development Goals provide another framework for designing information ethics curricula from the development perspective. Lack of development leads to poverty or vice versa and this infringes on the basic rights of the people. UN Secretary-General Ban Ki-moon says in the foreword to Millennium Development Goals Report 2010 that 'It is clear that improvements in the lives of the poor have been unacceptably slow, and some hard-won gains are being eroded by the climate, food and economic crises' (United Nations, 2010). The Millennium Development Goals (MDGs) are the most broadly supported and specific development goals worldwide. The eight time-bound goals provide benchmarks for tackling extreme poverty in its many dimensions. The goals include targets on income poverty, hunger, maternal and child mortality, disease, inadequate shelter, gender inequality, environmental degradation and the Global Partnership for Development. The MDGs are both global and local, and provide a framework for the entire international community to work together towards a common end - making sure that human development reaches everyone, everywhere. If these goals are achieved, world poverty will be cut by half, tens of millions of lives will be saved, and billions more people will have the opportunity to benefit from the global economy.

Capurro (2005) observes that information ethics is both descriptive and emancipator approach. As a descriptive theory it explores the power structures influencing information attitudes and policies in different cultures and contexts and reveals information harms that emerge as a consequence. As an emancipator, it develops normative criticisms of attitudes and practices in the information field at an individual and collective level and provides norma- 
tive guidelines to help mitigate the concerns identified in the descriptive stage. Capurro further states that information ethics can reveal the power structures that intertwine information professionals, knowledge workers and consumers in the African context thus, exposing the obligations and challenges faced by all members of the African information society. Information ethics can also provide normative guidelines to address and reduce the information harms and create a framework to protect the politics, culture, industry and economy of African nations, and support the development of a morally or ethically sensitive, sound and responsible information society within Africa. The Tshwane Declaration code of ethics for the information society referred to earlier, as well as, the African network for Information ethics platform and the African reader on information ethics can also serve as important sources of content as are principles of good governance and democracy.

Mason (1986) identifies four main ethical issues in an electronic age that may be desirable to cover in an information ethics curricula. These include: privacy (What information about one's self or one's associations must a person reveal to others, under what conditions and with what safeguards? What things can people keep to themselves and not be forced to reveal to others?); accuracy (Who is responsible for the authenticity, fidelity and accuracy of information?); accountability (Who is to be held accountable for errors in information and how is the injured party to be made whole?); property (Who owns information? What are the just and fair prices for its exchange? Who owns the channels, especially the airways, through which information is transmitted? How should access to this scarce resource be allocated?) and accessibility (What information does a person or an organization have a right or a privilege to obtain, under what conditions and with what safeguards?).

\section{Challenges of Integrating IE into the Curricula in Africa}

Several challenges stand in the way in developing an information ethics curriculum for Africa. With respect to access to information and communication technology, interoperability is technical issue that needs addressing because in the information age, access to systems is critical to enhance access to content. Interoperability of systems therefore becomes critical. It refers to the ability of information and communication technology systems and that of the business processes they support to exchange data and to enable sharing of information and knowledge (European Commission, 2004).

Country reports presented at the e-government and information ethics conference held in Magaliesburg South Africa in 2009 revealed several challenges that must be addressed if integration and subsequent teaching of IE has to be successful. These challenges relate to lack of enabling policies, poor ICT infrastructure, and bad governance. For example in a country such as Eritrea which emerged from war with Ethiopia, the government is cautious about releasing information lest it falls into wrong hands. To get information in the custody of the relevant government ministry is not easy as Eritrea has yet to enact freedom of information law. Even when permission is granted, the information storage and retrieval systems are dysfunctional. Eritrea also has no private press thus, negating freedom of speech and press. Eritrea also suffers from poor roads, health, energy and education facilities (with literacy level estimated at 50\%) necessary for promoting democratic practices. Eritrea also suffers from rampant poverty (E-Government Workshop, 2009).

Swaziland like Eritrea suffers from information related challenges that are of ethical nature. The country lacks cyber law to enhance transacting business online. Besides, as a kingdom, information about the state is highly regulated and freedom of speech and press is not guaranteed. Swaziland has also banned political party activities and freedom of assembly is confined to constituencies where political parties have a presence. Swaziland also faces poor infrastructure especially, in the rural areas where majority of the people live. These people remain largely unconnected from the rest of society due to the digital divide. Citizens are also generally not aware of their rights and obligations consequently, they have inadequate capacity to bring their governments to account. Both Eritrea and Swaziland suffer from rampant corruption in government (E-Government Workshop, 2009). Like Eritrea and Swaziland, Egypt scores poorly on freedom of expression. Government officials beat Ahmed Maher Ibrahim, a 27-year-old civil engineer for using Facebook to support calls for a general strike on May 4, 2008-President Mubarak's 80th birthday. The lack of democracy infringes on the rights of the people many countries fail to involve the public in electronically-enabled decision-making processes because politicians fear that e-democracy may result in a loss of power (Mahrer and Krimmer, 2005). 
In contrast to Eritrea and Swaziland, Botswana enjoys relative freedom of speech and free press. Besides, the government practices by and large democratic principles. However, the country faces some challenges that may border on infringement of ethical principles. Government has proposed a bill that aims to regulate the media. Additionally, government set up intelligence service agency in 2007 which citizens complain, it spies on people's privacy. Botswana also lacks community radios that would help effectively harness local content. In South Africa the government enacted freedom of information act which makes it possible for citizens to request and access information in custody of government. Government however, suffers poor reputation because of corruption, reported cases of censorship of public broadcaster, poor service delivery, low literacy levels, poverty of majority of its citizens, and interoperability challenges of different IT platforms making sharing of information cumbersome. The rest of African countries fall in the extremes of Eritrea and Swaziland or the progressive ones such as Botswana and South Africa.

Rotberg (2007) observes that E-government in Africa is unlikely to score highly on citizen trust. This is because by and large, e-government is still in the confines of government enclaves. While information on the "who is who" in the ministry, its organizational structure and mission will often be abundantly available, the average website will not have public service information, for instance on how to go about applying for a particular service, who the right office/ person to approach is, and where on the website to download and even electronically submit these application forms. The Ibrahim Index on African Governance reported the difficulties that were faced in collecting secondary data from government websites saying 'not all African countries have websites and where they do, they may not post useful data' (Rotberg, 2007:20). Often one finds that most e-government websites are designed on the basis of one-size-fits-all. This often creates a situation where some information may be perceived as offensive to some groups of people thus, creating distrust. Ocholla (2009) identified the following challenges of integrating information ethics in the curriculum in Africa including but not limited to: lack of capacity, the already bloated curriculum to accommodate new programmes or courses, and lack of awareness of the importance of information ethics by scholars.

In integrating information ethics in the curricula the other challenges that must be overcome include access and accessibility -digital divide and the ethical consequences of social exclusion. Furthermore, technology offers opportunity for wrong doing i.e. hacking, viruses, high cost of access, restrictive intellectual property rights, limited freedom of expression and censorship; lack of FOI; policy vacuums; intrusiveness of information; rapid technological development and danger of social exclusion. Despite these challenges, Africa has the potential to embrace information ethics and integrate it in the education curricula. Most countries are practicing some form of democratic governance with free press and freedom of assembly. Various technologies such as radio, TV, cordless telephones (Eritrea), VSATs, solar panels, etc are being applied to overcome digital divide. Efforts are being made to implement e-government (in most countries), establish data protection legal framework (South Africa) and introduce freedom of information (South Africa, Uganda, Zimbabwe, Kenya, etc). Scholars must continue on researching on issues of information ethics and pointing out where corrective measures are needed.

\section{Conclusion}

The author sought to demonstrate the growing importance for information ethics curricula in Africa. The efforts being made by scholars in Africa and abroad to mainstream information ethics in the curricula were outlined. This was followed by rationalizing why information ethics deserves to be mainstreamed into the curricula in Africa. Theoretical underpinning for IE was explored and the challenges for integrating in the curricula elucidated. The author noted that despite efforts being made to grow IE in Africa, the continent was trailing its counterparts especially Europe and North America with regard to the level of IE integration in the curriculum. Africa's IE content would be drawn from ubuntu philosophy, IE theories, WSIS principles of declaration, MDGs, UN Declaration of Human Rights, the African network for Information ethics platform, and the African reader on information ethics. For IE to be successfully mainstreamed into the curriculum, a number of challenges would have to be overcome such as: digital divide; interoperability of systems issues; lack of enabling policies, poor ICT infrastructure, and bad governance. Despite these challenges, Africa has the potential to integrate information ethics into the curricula as most countries are moving toward democratic governance with free press and freedom of assembly. Besides, various appropriate technologies such as radio, TV, cordless telephones, VSATs, solar panels and others are being applied to overcome digital divide. Moreover, 
efforts are being made to implement e-government in most countries and establish data protection legal framework. Scholars must however, continue researching on issues of information ethics in order to identify and point out where corrective measures are needed.

\section{References}

Brannigan, M.C. (2005). Ethics across cultures with PowerWeb ethics. N.Y. McGraw-Hill

Britz, J; Mutula, S.M. \& Ocholla, D. (2009). Partnership for African Information Ethics Curricula and Faculty Development. A proposal for Africa-US Higher Education Initiative Planning Grant. Wisconsin: UWM

Britz, J \& Buchanan, E. (2009). Ethics from bottomup? Immersive Ethics and LIS Curriculum. Journal of Information Ethics, 18(1), 3-5

Buchanan, E. (2004). Ethics in Library and Information Science: What are we Teaching. Journal of Information Ethics, 13(1), 51-50.

Capurro, $R$ (1998). Information and Information Ethics. Ideas to take Responsible Action in the Field of Information. Nachrichten Fiir Documentation, $39(1-4), 1-4$

Capurro, $R$ (2005). Information Ethics. Computer Society of India, 28(12), 7-10

Capurro, $R$ (2010). Information Ethics in Africa. Paper presented at WSIS Forum 2010, Geneva May 11, 2010.

Carbo, T. (2007). Information rights: trust and human dignity in e-government. International Review of Information Ethics, 7(9). [Online]. Available at: http://www.i-r-i-e.net [Accessed 8 December 2008].

Department of IT eTechnology Group (India) (2003). Assessment of central ministries and departments: e-governance readiness assessment 2003: Draft Report 48

E-Government Workshop (2009). Country reports on e-government in Botswana, Eritrea, South Africa \& Swaziland. UNESCO Training Workshop on Information Ethics and E-Government in sub Saharan Africa, 23-27 February 2009, Held at Mount Resort Magaliesburg, South Africa

Fallis, D. (2007). Information ethics for the twenty first century library professionals. Library $\mathrm{Hi}$ Tech, 25(1), 23-36.

European Commission (2004). European interoperability framework: interchange of data between administration IDA Working Document, Version 4.2. [Online]. Available at: http://europa.eu.int/ISPO/ida/export/files/en 11674.pdf [Accessed 8 December 2008].

European Commission (2005). Transforming public services. Report of the Ministerial eGovernment Conference, Manchester, UK. [Online]. Available at:

http://www.egov2005conference.gov.uk/docum ents/pdfs/eGovConference05_Summary.pdf [ACcessed 12 December 2008]

Froehlich, T. (2005). A brief history of information ethics. Computer Society of India 28(12), 11-13

Hamelink, C. (2003). Statement on communication rights. [Online]. Available at:

http://www.communicationrights.org/statement en.html [Accessed 20 August 2005).

Koren, M. (1996), Tell me! the right of the child to information. The Hague: NBLC

Mahrer, H. and Krimmer, R. (2005). Towards the enhancement of e-democracy: Identifying the notion of the middleman paradox. Journal of Information Systems, 15(1), 27-42.

Mason, R.O. (1986). Four ethical issues of the information age. Management Information Systems Quarterly 10(1) 5-12

Moore, G.E. (1988) . Principia ethica. New York: Promethus Books

Mutula, S.M. (2008). Local content development projects in Africa SA Jnl Libs and Info Sci, 74(2), 105-115

Mutula, S. M \& Raseroka, K (2006). Equipping youths with information literacy competencies to partake in national development (unpublished)

National Endowment for Financial Education (2006). Duty-based ethics, a framework for making decisions. [Online]. Available at: http://nefe.danielsfund.org/ethics/section_th ree/dbe.html [Accessed 24 June 2010]

Neumayer, E (2006). Self-interest, foreign need and good governance: are bilateral investment treaty programmes similar to aid allocation? Foreign Policy Analysis, 2(3), 245-268

Ocholla, Dennis N. (2009) Information Ethics Education in Africa. Where do we stand? International Information and Library Review, Vol.41,2,79-88 Raaflaub, Kurt. A; Ober, Josiah; Wallace, Robert. $W$ (2007). Origins of democracy in ancient Greece. Berkeley: University of California Press

Ramose, M.B (2002). Globalisation and ubuntu. In Coetzee, Pieter/Roux, Abraham (2002). Philoso- 
phy from Africa. A text with readings. Oxford: Oxford University Press.

Rotberg, R. (2007). The Ibrahim index on African governance: how we achieved our rankings. African Business, November 2007, No. 336. 20.

United Nations (2008). United Nations e-government survey 2008: From e-government to Connected governance. N. York: United Nations

UNESCO (2008). Ethical issues of information society [Online]. Available at:

http://www.unesco.org/webworld/en/ethicinformation-society [Accessed 26 July 2008].

United Nations (2010). Millennium Development Goals Report 2010. [Online]. Available at: http://www.un.org/millenniumgoals/ [Accessed 24 June 2010].

United Nations Development Programme (2010). What are the Millennium Development Goals? [Online]. Available at: http://www.undp.org/mdg/basics.shtml [Accessed 24 June 2010].

Vagaan, R.W. (2003). LIS education-repackaging infopreneurs or promoting value-based skills? New Library World, 104(3-5), 156-163).

WSIS (2003). World summit on the information society: Draft declaration of principles. Geneva: WSIS.

WSIS (2005). Tunis commitment and Tunis agenda for the information society. Retrieved February 14, 2006, from http://www.itu.int/wsis/ documents/doc_multi.asp? lang=en\&andid $=2266 / 2267$. 